\title{
Abatement vs. treatment for efficient diffuse source water pollution management in terrestrial-marine systems
}

\author{
P.C. Roebeling*\#, M.C. Cunha**, L. Arroja*, M.E. van Grieken*** \\ * CESAM - Department of Environment \& Planning, University of Aveiro, 3810-193 Aveiro, Portugal. E-mail: \\ peter.roebeling@ua.pt, arroja@ua.pt. \\ ** IMAR - Department of Civil Engineering, University of Coimbra, 3030-290 Coimbra, Portugal. E-mail: \\ mccunha@dec.uc.pt. \\ *** CSIRO Ecosystem Sciences, PO Box 2583, Brisbane QLD 4001, Australia. E-mail: \\ Martijn.Vangrieken@csiro.au. \\ \# Corresponding author. Tel.: +351 234370 387; Fax: +351 234370 309; E-mail: peter.roebeling@ua.pt.
}

\begin{abstract}
Marine ecosystems are affected by water pollution originating from coastal catchments. The delivery of water pollutants can be reduced through water pollution abatement as well as water pollution treatment and, hence, sustainable economic development of coastal regions requires balancing of the marginal costs from water pollution abatement and/or treatment and the associated marginal benefits from marine resource appreciation. Water pollution delivery reduction costs are, however, not equal across abatement and treatment options. In this paper an optimal control approach is developed and applied to explore welfare maximizing rates of water pollution abatement and/or treatment for efficient diffuse source water pollution management in terrestrial-marine systems. For the case of diffuse source Dissolved Inorganic Nitrogen (DIN) water pollution in the Tully-Murray region (Queensland, Australia), (agricultural) water pollution abatement cost, (wetland) water pollution treatment cost and marine benefit functions are determined to explore welfare maximizing rates of water pollution abatement and/or treatment. Provided partial (wetland) treatment costs and positive water quality improvement benefits, results show that welfare gains can be obtained, primarily, through diffuse source water pollution abatement (improved agricultural management practices) and, to a minor extent, through diffuse source water pollution treatment (wetland restoration).
\end{abstract}

Keywords: Environmental-economic analysis; diffuse source water pollution; abatement; treatment; improved agricultural management practices; wetland restoration; marine ecosystem values.

\section{Introduction}

Land use change and intensification in coastal catchments along the Great Barrier Reef (GBR) region of Australia have led to increased exports of diffuse-source water pollutants into the GBR lagoon over the past decades (Furnas, 2003). Among the key water pollutants, sediments, nutrients and pesticides, nitrogen (as nitrate) from agricultural fertiliser use has been identified as a priority terrestrially sourced pollutant (Brodie and Mitchell 2005; Webster et al., 2009). Associated levels of water pollution in the GBR lagoon are one of the biggest potential causes of reef degradation (Fabricius, 2005) which, consequently, may affect economic sectors, notably tourism and commercial/recreational fishery, that rely on the GBR for their income generation (Productivity Commission, 2003).

To protect environmental values of the GBR, Australian governments developed the Reef Water Quality Protection Plan (QDP\&C, 2003) which aims to 'halt and reverse the decline in water quality entering the Reef within 10 years' through the development of catchment Water Quality Improvement Plans (WQIPs). These WQIPs aim to reduce anthropogenically sourced pollutant delivery to the GBR lagoon, through improved management practices (pollution abatement) and restoration of wetland areas (pollution treatment; Binney, 2010). While the ability of wetlands to treat water pollution is recognized (Mitsch and Gosselink, 2000; McJannet, 2012), 
developed WQIPs mainly focus on improved management practices to abate diffuse source water pollution (Binney, 2010).

Costs of reducing diffuse source water pollution in the GBR lagoon are, however, significant (Binney, 2010). Sustainable economic development of coastal regions requires balancing of the marginal costs from reduced diffuse source water pollution delivery to the marine environment and the associated marginal benefits from marine resource appreciation (see Hart and Brady, 2002; Gren and Folmer, 2003; Roebeling et al., 2009b). Yet, diffuse source water pollution delivery reduction costs are not equal across abatement and treatment options and, hence, the question arises to what extent marine water quality improvement can efficiently be pursued through diffuse source water pollution abatement (improved agricultural management practices) and/or treatment (wetland restoration), respectively.

Numerous studies assess the cost-effectiveness of agricultural water pollution abatement options (e.g. Elofsson, 2003; Yang et al., 2005; Roebeling et al., 2009a, 2014; Lescot et al., 2013; Liu et al., 2014), wetland water pollution treatment options (e.g. Byström, 1998; Byström et al., 2000; Söderqvist, 2002; Gren, 2010) and both (agricultural) water pollution abatement and (diverse) water pollution treatment options (e.g. Byström, 2000; Ribaudo et al., 2001; Veeren and Tol, 2001; Gren, 2008; Gren et al., 2013). Only few studies explore efficient, welfare maximizing rates of (agricultural) water pollution abatement and/or water pollution treatment in terrestrialmarine systems. In particular, Goetz and Zilberman (2000), Hart and Brady (2002) and Roebeling et al. (2009b) explore welfare maximizing rates of (agricultural) water pollution abatement, Roebeling et al. (2011) explore welfare maximizing rates of (wetland) water pollution treatment, and Gren and Folmer (2003), Laukkanen and Huhtala (2008) and Laukkanen et al. (2009) explore welfare maximizing rates of (agricultural) water pollution abatement and (municipal) wastewater treatment.

In contribution to these earlier studies, an analytically tractable deterministic optimal control approach is developed and applied that allows to explore, simultaneously, welfare maximizing rates of diffuse source (agricultural) water pollution abatement as well as (wetland) water pollution treatment in terrestrialmarine systems. For the case of diffuse source Dissolved Inorganic Nitrogen (DIN) water pollution in the Tully-Murray region in the Wet Tropics of Queensland (Australia), (agricultural) water pollution abatement cost, (wetland) water pollution treatment cost and marine benefit functions are determined to explore to what extent water quality improvement in the GBR lagoon can efficiently be pursued through water pollution abatement (improved agricultural management practices) and/or water pollution treatment (wetland restoration).

In the next Section the deterministic optimal control approach is developed and solved analytically. Next parameter values for (agricultural) water pollution abatement cost, (wetland) water pollution treatment cost and marine benefit functions are determined to explore, in turn, welfare maximizing rates of (agricultural) water pollution abatement and (wetland) water pollution treatment in the Tully-Murray region. Finally, concluding remarks and recommendations are presented.

\section{Material and Methods}

To explore welfare $(W)$ maximizing rates of (agricultural) water pollution abatement as well as (wetland) water pollution treatment, the Catchment to Reef Optimal Water Pollution Abatement (CROWPA) modelling approach (see Roebeling et al., 2009b) is 
adapted to the case of DIN water pollution from fertiliser use by the key agricultural land uses as well as DIN water pollution treatment through wetland restoration in the Tully-Murray catchment in the Wet Tropics of Queensland, Australia.

Let $B_{t e r}\left(R_{t}\right)$ denote the benefits (net returns) from agricultural production that are a function of the rate of (agricultural) water pollution $R_{t}$ (control variable) ${ }^{1}$; let $C_{t e r}\left(T_{t}\right)$ denote the (wetland) water pollution treatment costs that are a function of the rate of (wetland) water pollution treatment $T_{t}$ (control variable); and let $B_{\operatorname{mar}}\left(P_{t}\right)$ denote the marine benefits from economic use values of marine resources that are a function of the level of water pollution $P_{t}$ (stock variable). The annual flow of (regional) net benefits $\pi\left(R_{t}, T_{t}, P_{t}\right)$ is given by the sum of agricultural benefits $B_{t e r}\left(R_{t}\right)$, (wetland) water pollution treatment costs $C_{t e r}\left(T_{t}\right)$ and marine benefits $B_{\operatorname{mar}}\left(P_{t}\right)$ :

$$
\begin{aligned}
\pi\left(R_{t}, T_{t}, P_{t}\right) & =B_{\text {ter }}\left(R_{t}\right)-C_{t e r}\left(T_{t}\right)+B_{\text {mar }}\left(P_{t}\right) \\
& =\left(\alpha_{1}+\alpha_{2} R_{t}-\alpha_{3} R_{t}^{2}\right)-\left(\alpha_{4}+\alpha_{5} T_{t}+\alpha_{6} T_{t}^{2}\right)+\left(\beta_{1}-\beta_{2} P_{t}\right)
\end{aligned}
$$

This specification acknowledges: i) decreasing marginal benefits from agricultural fertiliser use and, corresponding, (agricultural) water pollution $R_{t}$ (i.e. $\alpha_{1} \geq 0, \alpha_{2}>0$ and $\alpha_{3}>0$; ii) increasing marginal costs from (wetland) water pollution treatment $T_{t}$ (i.e. $\alpha_{4} \geq 0, \alpha_{5}>0$ and $\alpha_{6}>0$ ); and iii) constant marginal costs from marine water pollution $P_{t}$ (i.e. $\beta_{1} \geq 0$ and $\beta_{2}>0$ ). The corresponding optimal control welfare $(W)$ maximization problem is given by:

$$
\underset{R_{t}, T_{t}}{\operatorname{Max}} W=\int_{0}^{\infty}\left[\pi\left(R_{t}, T_{t}, P_{t}\right)\right] e^{-r t} d t
$$

subject to

$$
\dot{P}_{t}=b+R_{t}-T_{t}-a P_{t}
$$

with $P_{0}>0, R_{0}>0, T_{0}>0, P_{t} \geq 0, R_{t} \geq 0$ and $T_{t} \geq 0$, and where $r$ is the time discount rate, $\dot{P}_{t}$ is the equation of motion for $P_{t}$, and where a dot over a variable denotes the derivative of that variable with respect to time $t$. The equation of motion $\dot{P}_{t}$ (Eq. 3), depicting the intertemporal change in the level of marine water pollution $P_{t}$, is determined by the rate of non-agricultural water pollution $b$, the rate of (agricultural) water pollution $R_{t}$, the rate of (wetland) water pollution treatment $T_{t}$, and the fraction $a$ of total water pollution $P_{t}$ that is lost from the system through deposition, transport, uptake and other biophysical processes.

The current value Hamiltonian, while omitting time notation $t$, is now given by

$$
H=\left(\alpha_{1}+\alpha_{2} R-\alpha_{3} R^{2}\right)-\left(\alpha_{4}+\alpha_{5} T+\alpha_{6} T^{2}\right)+\left(\beta_{1}-\beta_{2} P\right)+\lambda(b+R-T-a P)
$$

where $\lambda$ is the costate variable. Assuming an interior solution, the necessary conditions for an optimum solution can be derived (i.e. $\delta H / \delta R=0 ; \delta H / \delta T=0 ; \delta P / \delta t=$ $\delta H / \delta \lambda ; \delta \lambda / \delta t=-\delta H / \delta P+r \lambda)$, and in the steady state $(\delta \lambda / \delta t=\delta P / \delta t=0)$ this is solved for the welfare maximizing rates of (agricultural) water pollution $R^{*}$, (wetland) water pollution treatment $T^{*}$ and level of water pollution $P^{*}$. These are given by:

\footnotetext{
${ }^{1}$ The specification of benefits from agricultural production as a function of the rate of (agricultural) water pollution is equivalent to the, commonly used, abatement cost function specification (Roebeling et al., 2009a, 2009b). This specification allows, however, to directly relate catchment-sourced rates of water pollution $\left(R_{t}\right)$ to marine levels of water pollution $\left(P_{t}\right)$ and, subsequent, load targets.
} 
Note that the welfare maximizing rate of (agricultural) water pollution $R^{*}$ is decreasing in $\alpha_{3}$ and $\beta_{2}$, and increasing in $\alpha_{2}, r$ and $a$ (Eq. 5), while the welfare maximizing rate of (wetland) water pollution treatment $T^{*}$ is increasing in $\beta_{2}$, and decreasing in $\alpha_{5}, \alpha_{6}, a$ and $r$ (Eq. 6). The welfare maximizing level of water pollution $P^{*}$ is decreasing in $T^{*}$ and $a$, and increasing in $R^{*}$ and $b$ (Eq. 7).

\section{Empirical Application}

The model described in the previous Section is now used to compare rates of (agricultural) water pollution abatement and (wetland) water pollution treatment as well as corresponding welfare implications in the Tully-Murray region. To this end, parameter values for agricultural benefit $B_{t e r}\left(R_{t}\right)$, (wetland) water pollution treatment cost $C_{t e r}\left(T_{t}\right)$ and marine benefit $B_{\operatorname{mar}}\left(P_{t}\right)$ functions are determined.

The agricultural benefit function $B_{t e r}\left(R_{t}\right)$ for the Tully-Murray catchment is derived using the Environmental Economic Spatial Investment Prioritization (EESIP) modelling approach, which integrates an agricultural production system simulation model, a catchment water quality model and a spatial environmental-economic landuse model (see Roebeling et al., 2009a). The agricultural production system simulation model assesses plot-level production and water pollution characteristics for hundreds of agricultural land use and management practices, the catchment water quality model assesses the relationship between local water pollution supply (i.e. gross supply of water pollutants to streams and rivers) and end-of-catchment water pollution delivery (i.e. net delivery of water pollutants to the coast) and, finally, the spatial environmental-economic land-use model allocates agricultural land use and management practices such that they contribute most to agricultural benefits given specified end-of-catchment load targets.

Roebeling et al. (2009b) use EESIP to estimate benefits from sugarcane and grazing production at increasing rates of allowed DIN water pollution delivery to the GBR catchment lagoon and, in turn, fit the corresponding quadratic agricultural benefit functions (see Eq. 1). Summation of these industry-specific agricultural benefit functions for the sugarcane and grazing industries, yields the agricultural benefit function (in 2014 million $\left.\mathrm{A} \$ \mathrm{yr}^{-1}\right)^{2}$

$$
B_{\text {ter }}\left(R_{t}\right)=69.423+0.1139 R_{t}-0.00012 R_{t}^{2}
$$

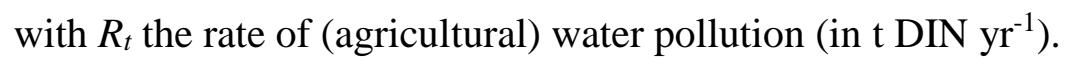

The (wetland) water pollution treatment cost function $C_{t e r}\left(T_{t}\right)$ is taken from Roebeling et al. (2011). Based on secondary information for extensive treatment technologies (i.e. constructed/restored managed wetlands), they construct a database $(\mathrm{N}=41)$ for wetland capacity, area, pollution concentration, treatment efficiency, construction costs and operation \& maintenance costs. Wetland water pollution treatment rates (in $\mathrm{t}$ DIN $\mathrm{yr}^{-1}$ ) were calculated using DIN concentration, wetland

\footnotetext{
${ }^{2}$ All monetary values are updated to $2014 \mathrm{~A} \$$ using the consumer price index (World Bank, 2015).
} 
capacity and wetland treatment efficiency data, and all cost data were transferred to

The marine benefit function $B_{\operatorname{mar}}\left(P_{t}\right)$ from use values of the GBR, is taken from Roebeling et al. (2011. In line with earlier studies and based on tourism, commercial fishery and recreational fishery values in the Tully-Murray region, they take marine benefits to be linearly decreasing in the level of marine water pollution $P_{t}$ (see Eq. 1). The marine tourism producer surplus equals about 6.1 million $\mathrm{A} \$$ per year (based on Productivity Commission, 2003; GBRMPA, 2004), the commercial and recreational fishery producer surplus equals around 11.4 million A $\$$ per year (based on Fenton and Marshall, 2001; Productivity Commission, 2003) and, hence, the use value of the GBR in the Tully-Murray region (in its current state) amounts to about 17.5 million $\mathrm{A} \$$ per year. The marine benefit function becomes (in 2014 million $\mathrm{A} \$ \mathrm{yr}^{-1}$ )

$$
B_{\text {mar }}\left(P_{t}\right)=\left(17.5+\beta_{2} P_{0}\right)-\beta_{2} P_{t}
$$

where $P_{0}$ is the current baseline level of (GBR lagoon) water pollution (in t DIN), and noting that the first term on the right-hand-side determines the maximum attainable marine benefits $\beta_{1}$.

While the effect of marine water pollution on reef health is widely recognized (Furnas, 2003; Fabricius, 2005), the marginal costs from marine water pollution $\beta_{2}$ are less well known (Wielgus et al., 2002; Keeler et al., 2012). Keeler et al. (2012) argue that there is no generic framework linking continuous changes in water quality to changes in multiple ecosystem services - thus failing to achieve full-accounting of associated changes in ecosystem service values. Thus, a sensitivity analysis with respect to $\beta_{2}$ is performed in the next section.

\section{Results and Discussion}

Based on abovementioned parameter values for the Tully-Murray region, first costs associated with (agricultural) water pollution abatement and (wetland) water pollution treatment are analysed and compared. Next welfare maximizing rates of (agricultural) water pollution $R^{*}$ and (wetland) water pollution treatment $T^{*}$ for varying values of marginal marine water pollution costs $\beta_{2}$ are explored. As pollution treatment is one 
of many ecosystem services provided by wetlands (Costanza et al., 1997; Mitsch and Gosselink, 2000), estimated at about $10 \%$ of the total ecosystem service value of floodplain wetlands (Costanza et al., 1997; De Groot et al., 2012), results are presented for full and partial (wetland) water pollution treatment costs $B_{t e r}\left(T_{t}\right)$.

\section{Water pollution abatement and treatment costs}

To compare the costs of (wetland) water pollution treatment $T_{t}$ and (agricultural) water pollution abatement $A_{t}$, the agricultural benefit function $B_{t e r}\left(R_{t}\right)$ is rewritten in terms of the water pollution abatement cost function $C_{\text {ter }}\left(A_{t}\right)$. Using Eq. (8) while noting that $C_{t e r}\left(A_{t}\right)=B_{t e r}\left(R_{0}\right)-B_{t e r}\left(R_{t}\right)$ and $A_{t}=R_{0}-R_{t}$ (with $R_{0}$ the current rate of agricultural water pollution), it can be verified that the (agricultural) water pollution abatement cost function is given by (in 2014 million $\mathrm{A} \$ \mathrm{yr}^{-1}$ )

$$
C_{\text {ter }}\left(A_{t}\right)=-0.0183 A_{t}+0.00012 A_{t}^{2}
$$

with $A_{t}$ the rate of (agricultural) water pollution abatement (in t DIN $\mathrm{yr}^{-1}$ ).

Graphical representation of the (agricultural) water pollution abatement cost function (see Eq. 11; Fig. 1) shows that considerable DIN water quality improvements can be obtained at a negative cost and, thus, a private benefit to the agricultural sector. Maximum benefits are expected to be obtained through a reduction in DIN water pollution of about 15\% ( 75 t DIN), and are facilitated through the adoption of winwin management practices in sugarcane production. Win-win management practices in sugarcane production include the adoption of more nitrogen-efficient management practices, like economic optimum rates of nitrogen application, split nitrogen application and nitrogen replacement (see Roebeling et al., 2009a, 2009b).

While reductions in DIN water pollution beyond $15 \%$ come at a cost to the agricultural sector, reductions in DIN water pollution of up to almost $30 \%(\sim 150 \mathrm{t}$ DIN) are expected to come at no additional cost as compared to the current situation. Reductions in DIN water pollution of over $30 \%$ come at a (significant) cost to the agricultural sector - up to about 10.8 million $\mathrm{A} \$ \mathrm{yr}^{-1}$ for a $70 \%(\sim 380 \mathrm{t}$ DIN) decrease in DIN water pollution. This due to the adoption of lose-win management practices in combination with a reduction in production area (see Roebeling et al., 2009a, 2009b).

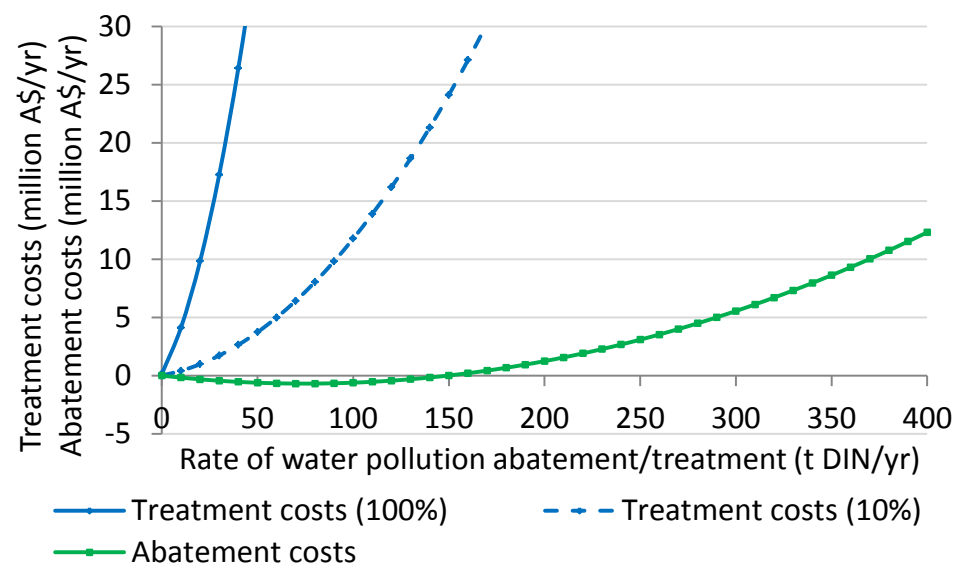

Figure 1 Total (agricultural) DIN water pollution abatement cost functions and (wetland) DIN water pollution treatment cost functions $\left(B_{t e r}\left(T_{t}\right)=100 \%\right.$ and $\left.10 \%\right)$ for the Tully-Murray catchment.

Graphical representation of the (wetland) water pollution treatment cost function (see Eq. 9; Fig. 1) shows that all treatment comes at a cost. For a 5\% ( 25 t DIN) decrease in DIN water pollution, (wetland) water pollution treatment costs amount up 
to about 13.5 million $\mathrm{A} \$ \mathrm{yr}^{-1}$ and 1.4 million $\mathrm{A} \$ \mathrm{yr}^{-1}$ in case full $(100 \%)$ and partial capacity $\left(<5 \mathrm{t} \mathrm{DIN} \mathrm{yr}^{-1}\right)$, marginal (wetland) water pollution treatment costs are estimated at between 38 and 320 thousand $\mathrm{A} \$ \mathrm{t}^{-1} \mathrm{DIN}$ - in line with Byström (1998) and Gren (2008) who estimate marginal (wetland) water pollution treatment costs at between 4 and 205 thousand $\mathrm{A} \$ \mathrm{t}^{-1}$ DIN. Ribaudo et al. (2001), however, estimate average (wetland) water pollution treatment costs at only 25 thousand $A \$ t^{-1} \mathrm{DIN}$, though they do not consider wetland operation \& maintenance costs.

Comparison of the (agricultural) water pollution abatement and (wetland) water pollution treatment cost functions shows that diffuse source (wetland) water pollution treatment options are relatively expensive. This in line with Ribaudo et al. (2001) and Gren (2008), who show that the unit cost of diffuse source (wetland) water pollution treatment can be up to twenty times more expensive than the unit cost of diffuse source (agricultural) water pollution abatement. For the Tully-Murray case study these differences are even larger as, in contrast to these earlier studies, win-win (agricultural) water pollution abatement options are specifically taken into account.

\section{Welfare maximizing rates of water pollution abatement and treatment}

For the reference year 2005, the current rate of (agricultural) water pollution $R_{0}$ equals

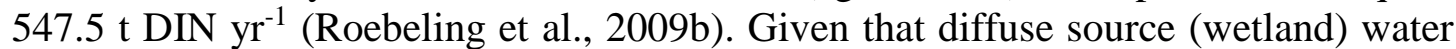

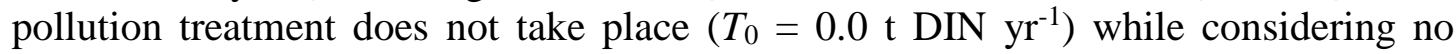
other sources $(b=0)$ and no re-suspension $(a=1)$ of water pollutants, the current level of (GBR lagoon) water pollution $P_{0}$ equals $547.5 \mathrm{t} \mathrm{DIN} \mathrm{yr}{ }^{-1}$ (using Eq. 7). The corresponding (regional) net benefit $\pi_{0}$ equals 112.9 million $\mathrm{A} \$ \mathrm{yr}^{-1}$ (using Eq. 8, 9 and $\left.10 ; \beta_{2}=0\right)$. Given a time discount rate $r$ of $5 \% \mathrm{yr}^{-1}$, the welfare maximizing $R^{*}$, $T^{*}, P^{*}$ and $\pi^{*}$ for values of marine water pollution costs $\beta_{2}$ and (wetland) water pollution treatment costs $B_{t e r}\left(T_{t}\right)$ are given in Table 1 .

Table 1 Welfare maximizing rates of (agricultural) DIN water pollution $R^{*}$, rates of (wetland) DIN water pollution treatment $T^{*}$, levels of (GBR lagoon) DIN water pollution $P^{*}$ and levels of (regional) net benefits $\pi^{*}$, for values of (marine) DIN water pollution costs $\beta_{2}$ and (wetland) DIN water pollution treatment costs $\left(B_{t e r}\left(T_{t}\right)=100 \%\right.$ and $\left.10 \%\right)$ for the Tully-Murray region.

\begin{tabular}{|c|c|c|c|c|c|c|}
\hline & \multicolumn{3}{|c|}{ Water pollution treatment costs $100 \%$} & \multicolumn{3}{|c|}{ Water pollution treatment costs $10 \%$} \\
\hline & $\beta_{2}=0.00$ & $\beta_{2}=0.04$ & $\beta_{2}=0.08$ & $\beta_{2}=0.00$ & $\beta_{2}=0.04$ & $\beta_{2}=0.08$ \\
\hline$R^{*}(\mathrm{t} \mathrm{DIN/yr)}$ & 471.7 & 313.9 & 156.1 & 471.7 & 313.9 & 156.1 \\
\hline$T^{*}(\mathrm{t}$ DIN/yr) & 0.0 & 0.0 & 0.0 & 0.0 & 4.0 & 26.1 \\
\hline$P^{*}(\mathrm{t}$ DIN/yr $)$ & 471.7 & 313.9 & 156.1 & 471.7 & 309.9 & 130.0 \\
\hline$\pi^{*}($ million $\mathrm{A} \$ / \mathrm{yr})$ & 113.6 & 119.9 & 132.9 & 113.7 & 120.1 & 133.7 \\
\hline
\end{tabular}

When downstream costs from DIN water pollution (i.e. $\beta_{2}=0$ ) are ignored, maximum welfare gains can be obtained through a reduction in (agricultural) DIN water pollution of about $15 \%(\sim 75 \mathrm{t}$ DIN $)-$ i.e. through the adoption of win-win management practices (see previous Section). DIN water pollution treatment (wetland) does not contribute to welfare $\left(T^{*}=0\right)$, as treatment involves considerable costs (see previous Section) while there are no associated benefits from water quality improvement (given $\beta_{2}=0$ ). The level of (GBR lagoon) water pollution decreases, as a result, with almost $15 \%$ and (regional) net benefit increases with about $1 \%$ to 113.6 million A $\$$ per year.

When downstream costs from DIN water pollution (i.e. $\beta_{2}>0$ ) are acknowledged, welfare gains can be obtained through sizable reductions in (agricultural) water pollution and some (wetland) water pollution treatment. In case downstream costs 
from water pollution $\beta_{2}$ equal $40,000 \$ \mathrm{t}^{-1}$ DIN (i.e. $\beta_{2}=0.04$ ) or even $80,000 \$ \mathrm{t}^{-1} \mathrm{DIN}$ (i.e. $\beta_{2}=0.08$ ), maximum welfare gains are obtained through a reduction in (agricultural) rates and corresponding (GBR lagoon) levels of DIN water pollution of $43 \%$ and $71 \%$, respectively. Wetland water pollution treatment only takes place when partial treatment costs are considered, with wetlands treating up to $26.1 \mathrm{t}$ DIN per year (10\% treatments costs). Thus, levels of (GBR lagoon) water pollution decrease with another $1 \%\left(\beta_{2}=0.04\right)$ to $5 \%\left(\beta_{2}=0.08\right)$. Regional net benefits increase with between $6 \%\left(\beta_{2}=0.04\right)$ and $18 \%\left(\beta_{2}=0.08\right)$, while noting that additional welfare gains from (wetland) water pollution treatment are relatively small $(<1 \%)$.

Hence, it is shown that welfare gains can be obtained, primarily, through diffuse source water pollution abatement (improved agricultural management practices) and, to a minor extent, through diffuse source water pollution treatment (wetland restoration). This in contrast with studies assessing welfare gains from diffuse source (agricultural) water pollution abatement and point source (municipal) water pollution treatment, that indicate substantial welfare gains from investments in (municipal) wastewater treatment plants (e.g. Laukkanen and Huhtala, 2008).

\section{Conclusions}

A deterministic optimal control approach was developed and applied to explore, simultaneously, welfare maximizing rates of (agricultural) water pollution abatement as well as (wetland) water pollution treatment for efficient diffuse source water pollution management in terrestrial-marine systems. In contrast to earlier studies an analytically tractable solution concept is presented, while providing an indication of the extent to which diffuse source water pollution delivery to the marine environment can efficiently be controlled by means of water pollution abatement (through improved agricultural management practices) and/or water pollution treatment (through wetland restoration), respectively.

Analytical results indicate that the welfare maximizing rates of (agricultural) water pollution and (wetland) water pollution treatment are, respectively, decreasing and increasing in the downstream costs from (GBR lagoon) water pollution. The level of downstream (GBR lagoon) water pollution is increasing in the rate of (agricultural) water pollution and decreasing in the rate of (wetland) water pollution treatment. Numerical results show that (wetland) water pollution treatment only leads to welfare gains when partial treatment costs and positive downstream water pollution costs are considered, while (agricultural) water pollution abatement leads to welfare gains even when downstream costs from water pollution are ignored.

Provided that pollution treatment is estimated at about $10 \%$ of the total ecosystem service value of floodplain wetlands, it is shown that welfare gains can be obtained, primarily, through diffuse source water pollution abatement (improved agricultural management practices) and, to a minor extent, through diffuse source water pollution treatment (wetland restoration) in the Tully-Murray catchment. While wetland research in temperate locations has been extensive and generally supports the role of managed wetlands as filters for water pollution, the effectiveness of (managed) wetlands in tropical environments is largely unknown. Hence, it is stressed that costeffectiveness studies of (managed) tropical wetlands are needed to confirm the validity of the used (wetland) water pollution treatment cost estimates. 


\section{Acknowledgements}

This paper has been developed in the context of: i) the Iberian Trans-boundary Water Management (IB-TWM) project funded by the Fundação para a Ciência $e$ a Tecnologia (FCT; PTDC/AAC-AMB/104301/2008) and the Fundo Europeu de Desenvolvimento Regional (FEDER; FCOMP-01-0124-FEDER-011867) and ii) the DESAFIO project funded by the European Union $7^{\text {th }}$ Framework Program (EU-7FP; $\mathrm{N}^{\mathrm{o}}$ 320303). In addition, this work was supported by the EU-COMPETE and FCT within the context of the projects PEst-C/MAR/LA0017/2013 and UID/AMB/50017/2013.

\section{References}

Binney, J. (2010). The Economic and Social Impacts of Protecting Environmental Values in the Great Barrier Reef Catchment Waterways and Reef Lagoon. Marsden Jacob Associates for the Department of Environment and Resource Management, Brisbane, Australia.

Brodie, J., and Mitchell, A.W. (2005). Nutrients in Australian tropical rivers: changes with agricultural development and implications for receiving environments. Marine and Freshwater Research, 56, 279302.

Byström, O. (1998). The nitrogen abatement cost in wetlands. Ecological Economics, 26, 321-331.

Byström, O. (2000). The replacement value of wetlands in Sweden. Environmental and Resource Economics, 16, 347-362.

Byström, O., Andersson, H. and Gren, I.M. (2000). Economic criteria for using wetlands as nitrogen sinks under uncertainty. Ecological Economics, 35, 35-45.

Costanza, R., d'Arge, R., de Groot, R., Farber, S., Grasso, M., Hannon, B., Naeem, S., Limburg, K., Paruelo, J., O'Neill, R.V., Raskin, R., Sutton, P. and Van den Belt, M. (1997). The value of the world's ecosystem services and natural capital. Nature, 387, 253-260.

De Groot, R. Brander, L., Van der Ploeg, S., Costanza, R., Bernard, F., Braat, L., Christie, M., Crossman, N., Ghermandi, A., Hein, L., Hussain, S., Kumar, P., McVittie, A., Portela, R., Rodriguez, L.C., Ten Brink, P. and Van Beukering, P. (2012). Global estimates of the value of ecosystems and their services in monetary units. Ecosystem Services, 1, 50-61.

Elofsson, K. (2003). Cost-effective reductions of stochastic agricultural loads to the Baltic Sea. Ecological Economics, 47, 13-31.

Fabricius, K. E. (2005). Effects of terrestrial runoff on the ecology of corals and coral reefs: review and synthesis. Marine Pollution Bulletin, 50, 125-146.

Fenton, D.M. and Marshall, N.A. (2001). A Guide to the Fishers of Queensland, Part A: TRC Analysis and Social Profiles of Queensland's Commercial Fishing Industry. CRC Reef Research Centre, Technical Report 36, Townsville, Australia.

Furnas, M. (2003). Catchments and Corals: Terrestrial Runoff to the Great Barrier Reef. Australian Institute of Marine Science (AIMS), Townsville, Australia.

GBRMPA (2004). Data from Environmental Management Charge. Great Barrier Reef Marine Park Authority (GBRMPA), Townsville, Australia. Web-site: http://www.gbrmpa.gov.au/corp site/key issues/tourism/gbr visitation/page 02.html, viewed June 2004.

Goetz, R.U. and Zilberman, D. (2000). The dynamics of spatial pollution: the case of phosphorus runoff from agricultural land. Journal of Economic Dynamics and Control, 24, 143-163.

Gren, I.M. (2008). Adaptation and mitigation strategies for controlling stochastic water pollution: an application to the Baltic Sea. Ecological Economics, 66, 337-347.

Gren, I.M. (2010). Resilience value of constructed coastal wetlands for combating eutrophication. Ocean \& Coastal Management, 53, 358-365.

Gren, I.M. and Folmer, H. (2003). Cooperation with respect to cleaning of an international water body with stochastic environmental damage: the case of the Baltic Sea. Ecological Economics, 47, 33-42.

Gren, I.M., Savchuk, O.P. and Jansson, T. (2013). Cost-effective spatial and dynamic management of a eutrophied Baltic Sea. Marine Resource Economics, 28, 263-284.

Hart, R. and Brady, M. (2002). Nitrogen in the Baltic Sea - policy implications of stock effects. Journal of Environmental Management, 66, 91-103.

Keeler, B.L., Polasky, S., Brauman, K.A., Johnson, K.A., Finlay, J.C., O’Neill, A., Kovacs, K. and Dalzell, B. (2012). Linking water quality and well-being for improved assessment and valuation of ecosystem services. PNAS, 109(45), 18619-18624. 
Laukkanen, M. and Huhtala, A. (2008). Optimal management of a eutrophied coastal ecosystem: balancing agricultural and municipal abatement measures. Environmental and Resource Economics, 39, 139-159.

Laukkanen, M., Ekholm, P., Huhtala, A., Pitkänen, H., Kiirikki, M., Rantanen, P. and Inkala, A. (2009). Integrating ecological and economic modeling of eutrophication: toward optimal solutions for a coastal area suffering from sediment release of fhosphorus. Ambio, 38(4), 225-235.

Lescot, J.M., Bordenave, P., Petit, K. and Leccia, O. (2013). A spatially-distributed cost-effectiveness analysis framework for controlling water pollution. Environmental Modelling \& Software, 41,107-122.

Liu, R., Zhang, P., Wang, X., Wang, J., Yu, W. and Shen, Z. (2014). Cost-effectiveness and costbenefit analysis of BMPs in controlling agricultural nonpoint source pollution in China based on the SWAT model. Environmental Monitoring and Assessment, 186(12), 9011-9022.

McJannet, D., Wallace, J., Keen, R., Hawdon, A. and Kemei, J. (2012). The filtering capacity of a tropical riverine wetland: II. Sediment and nutrient balances. Hydrological Processes, 26(1), 53-72.

Mitsch, W.J. and Gosselink, J.G. (2000). The value of wetlands: importance of scale and landscape setting. Ecological Economics, 35, 25-33.

Productivity Commission (2003). Industries, Land Use and Water Quality in the Great Barrier Reef Catchment. Research Report, Canberra, Australia.

Ribaudo, M.O., Heimlich, R., Claassen, R. and Peters, M. (2001). Least-cost management of nonpoint source pollution: source reduction versus interception strategies for controlling nitrogen loss in the Mississippi Basin. Ecological Economics, 37, 183-197.

Roebeling, P.C., Van Grieken, M.E., Webster, A.J., Biggs, J. and Thorburn, P. (2009a). Cost-effective water quality improvement in linked terrestrial and marine ecosystems: a spatial environmentaleconomic modelling approach. Marine and Freshwater Research, 60, 1150-1158.

Roebeling, P.C., Hendrix, E.M.T. and Van Grieken, M.E. (2009b). Exploring industry specific social welfare maximizing rates of water pollution abatement in linked terrestrial and marine ecosystems. Journal of Coastal Research, 56, 1681-1685.

Roebeling P.C., Cunha, M.C., Arroja, L. and Van Grieken, M.E. (2011). Agricultural water pollution treatment for efficient water quality improvement in linked terrestrial and marine ecosystems. Journal of Coastal Research, 64, 1936-1940.

Roebeling P.C., Rocha J., Nunes J.P., Fidelis T., Alves H. and Fonseca S. (2014). Using the Soil and Water Assessment Tool to estimate dissolved inorganic nitrogen water pollution abatement cost functions in Central Portugal. Journal of Environmental Quality, 43(1), 168-176.

Söderqvist, T. (2002). Constructed wetlands as nitrogen sinks in southern Sweden: an empirical analysis of cost determinants. Ecological Engineering, 19, 161-173.

QDP\&C (2003). Reef water quality protection plan for catchments adjacent to the Great Barrier Reef world heritage area. Queensland Department of Premier and Cabinet (QDP\&C), Brisbane, Australia.

Veeren, R.J.H.M. and Tol, R.S.J. (2001), Benefits of a reallocation of nitrate emission reductions in the Rhine river basin. Environmental and Resource Economics, 18, 19-41.

Webster A.J., Thorburn P.J., Roebeling P.C., Horan H.L. and Biggs J.S. (2009). The expected impact of climate change on nitrogen losses from sugarcane production in the Wet Tropics of Australia. Marine and Freshwater Research, 60, 1159-1164.

Wielgus, J., Chadwick-Furman, N.E., Dubinsky, Z., Shechter, M. and Zeitouni, N. (2002). Doseresponse modeling of recreationally important coral-reef attributes: a review and potential application to the economic valuation of damage. Coral Reefs, 21, 253259.

World Bank (2015). World Development Indicators 2015. World Bank, Washington, DC.

Yang, W., Sheng, C., and Voroney, P. (2005). Spatial targeting of conservation tillage to improve water quality and carbon retention benefits. Canadian Journal of Agricultural Economics, 53, 477-500. 